\section{(2) \\ BRAZIULIAN JOURNAL \\ OF MEDICAL AND BIOLOGICAL RESEARCH}

www.bjournal.com.br
ISSN 0100-879X

Volume 45 (3) 179-290 March 2012

BIOMIEDICAL SCIENCES

AND

CLINICAL INVESTIGATION

Braz J Med Biol Res, March 2012, Volume 45(3) 264-272

doi: 10.1590/S0100-879X2012007500010

Increased immunohistochemical expression of YKL-40 in the spleen of patients with portal hypertension

Dong Wang, Jian-Guo Lu, Qing Wang, Xi-Lin Du, Rui Dong, Peng Wang, Lei Zhao, Xue Jiang and Li-Juan Yuan

The Brazilian Journal of Medical and Biological Research is partially financed by

\section{Q QNPPq}

Ministério da Ciência e Tecnologia

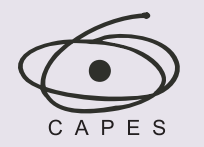

Ministério da Educação

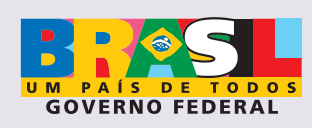

DTFAPESP
Institutional Sponsors

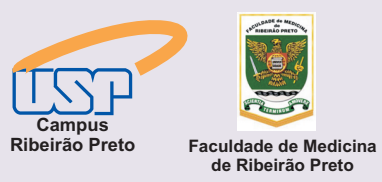

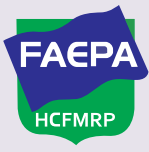

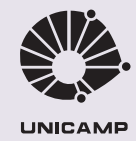

UNICAMP $\oplus$ SHIMADZu

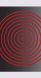

М다맘

Associaçäo
Fundo
de Incentivo delincentivo
âpesquisa

Explore High - Performance MS Orbitrap Technology andilica Thermo 


\title{
Increased immunohistochemical expression of YKL-40 in the spleen of patients with portal hypertension
}

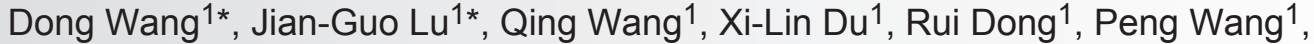 \\ Lei Zhao ${ }^{1}$, Xue Jiang ${ }^{2}$ and Li-Juan Yuan ${ }^{2}$
}

${ }^{1}$ Department of General Surgery, The Second Affiliated Hospital, Fourth Military Medical University, Xi'an, China 2Laboratory of General Surgery, The Second Affiliated Hospital, Fourth Military Medical University, Xi'an, China

\begin{abstract}
YKL-40 has been identified as a growth factor in connective tissue cells and also a migration factor in vascular smooth muscle cells. To a large extent, the increase of serum YKL-40 is attributed to liver fibrosis and asthma. However, the relationship of the expression and clinical/prognostic significance of $\mathrm{YKL}-40$ to the splenomegaly of patients with portal hypertension is unclear. In the present study, the expression of YKL-40 was studied by immunohistochemistry in 48 splenomegaly tissue samples from patients with portal hypertension and in 14 normal spleen specimens. All specimens were quickly stored at $-80^{\circ} \mathrm{C}$ after resection. Primary antibodies YKL-40 (1:150 dilution, rabbit polyclonal IgG) and MMP-9 (1:200 dilution, rabbit monoclonal IgG) and antirabbit immunoglobulins (HRP K4010) were used in this study. The relationship of clinicopathologic features with YKL-40 is presented. The expression of YKL-40 indicated by increased immunochemical reactivity was significantly up-regulated in splenomegaly tissues compared to normal spleen tissues. Overexpression of YKL-40 was found in $68.8 \%$ of splenomegaly tissues and was significantly associated with Child-Pugh classification $(P=0.000)$, free portal pressure (correlation coefficient $=0.499$, $P<0.01$ ) and spleen fibrosis (correlation coefficient $=0.857, P<0.01$ ). Further study showed a significant correlation between YKL-40 and MMP-9 (correlation coefficient $=-0.839, \mathrm{P}<0.01$ ), indicating that YKL-40 might be an accelerator of spleen tissue remodeling by inhibiting the expression of MMP-9. In conclusion, YKL-40 is an important factor involved in the remodeling of spleen tissue of portal hypertension patients and can be used as a therapeutic target for splenomegaly.
\end{abstract}

Key words: YKL-40; MMP-9; Splenomegaly; Fibrosis; Portal hypertension; Immunohistochemistry

\section{Introduction}

Splenomegaly is one of the complications of portal hypertension and chronic liver diseases that can influence patient morbidity and quality of life (1). The incidence of splenomegaly in cirrhosis ranges from 36 to $92 \%$ in different series (2). Especially in China, decompensated cirrhosis induced by viral hepatitis is an important cause of splenomegaly. In many cases, patients with portal hypertension simultaneously have splenomegaly and hypersplenism. They have no special symptoms related to splenomegaly but have symptoms related to hypersplenism. Occasionally, patients do not have any symptoms until they touched the enlarged spleen in the abdomen inadvertently. Splenomegaly may lead to the extrinsic compression of abdominal organs and therefore result in corresponding symptoms.
Overlarge spleens may magnify the risk for spontaneous rupture or rupture after minor trauma (1). To date, there is no specific medical therapy for splenomegaly.

YKL-40, also called human cartilage glycoprotein-39 (HC-gp39) and chitinase-3-like-1 (CHI3L1), is a heparin- and chitin-binding glycoprotein with a molecular mass of $40 \mathrm{kDa}$. It is highly conserved phylogenetically and belongs to 'mammalian chitinase-like proteins', but has no chitinase activity (3-8). The details of the physiological function of YKL-40 are unknown. It has been reported that this glycoprotein may contribute to tissue remodeling and extracellular matrix (ECM) degradation (9). An intense expression of YKL-40 protein in alveolar macrophages of idiopathic pulmonary fibrosis patients and of asthma patients demonstrates that

Correspondence: Jian-Guo Lu and Xi-Lin Du, Department of General Surgery, The Second Affiliated Hospital, Fourth Military Medical University, 1 Xin Si Road, Xi'an, China. E-mail: lujguo@fmmu.edu.cn and dxlin0705@163.com

*These authors contributed equally to this study.

Received January 22, 2011. Accepted January 4, 2012. Available online January 27, 2012. Published March 19, 2012. 
it is involved in tissue remodeling and fibrosis $(10,11)$. YKL-40 also induces the proliferation of chondrocytes and synovial cells (12). Furthermore, YKL-40 was found to induce coordination of membrane-bound receptor syndecan-1 and integrin alpha ( $v$ ) beta (3) to activate an intracellular signaling cascade, including focal adhesion kinase and mitogen-activated protein kinase extracellular signal-related kinase $1 / 2$ in endothelial cells (13). Collectively, these data suggest that $Y K L-40$ is involved in the pathologic process of human diseases involving tissue remodeling.

Matrix metalloproteinases (MMPs) are a family of proteolytic enzymes that contain $\mathrm{Zn}^{2+}, \mathrm{Ca}^{2+}$, and other metal ions. Accumulating evidence has indicated that MMPs play an essential role in fibrogenesis. Traditional substrates of MMPs are components of the ECM, such as collagen, laminin, and fibronectin. More than 20 enzymes have been identified as MMPs in mammals. MMP-9, an important member of the MMP family, functions in the degradation of almost all types of ECM, such as collagen I, collagen IV, collagen V, collagen VII, collagen X, collagen XI, fibronectin, elastin, and proteoglycans. Recent studies have shown that YKL-40 might play a role in fibrogenesis through MMP-9. Thus, in the present study, the relationship between expression of YKL-40 and of MMP-9 will also be explored.

Traditionally, splenomegaly in portal hypertension is thought to be a mere consequence of the rise of portal venous pressure and the increased resistance to splenic blood outflow (14), although there is a relatively weak correlation between portal venous pressure and spleen size. Recently, the role of tissue hyperplasia in congested splenomegaly has also been reported (15). Thus, we hypothesized that YKL-40 may play a role in the process of splenomegaly in portal hypertension. We also evaluated the expression of MMP-9 in splenomegaly and the relationship between YKL-40 and MMP-9 expression measured by immunohistochemistry.

\section{Material and Methods}

\section{Patients and samples}

Forty-eight splenomegaly specimens were obtained from consecutive patients submitted to full or partial splenectomy [33 men and 15 women with a median age of 44 years (range: 19-69)] referred to the Department of General Surgery between January 2009 and December 2009 at the Second Affiliated Hospital, Fourth Military Medical University, Xi'an, China. The diagnosis of portal hypertension was based on accepted biochemical and clinical criteria (16). In order to lower portal pressure and to alleviate clinical signs of portal hypertension (e.g., ascites, esophageal and gastric variceal bleeding, hypersplenism, splenomegaly, etc.), splenectomy was carried out with periesophagogastric devascularization or partial splenectomy was performed with a distal splenorenal shunt plus periesophagogastric devascularization after comprehensive evaluation. All patients with portal hypertension had suffered from liver cirrhosis, 41 patients had posthepatic cirrhosis [hepatitis $B$ $(\mathrm{N}=35)$, hepatitis $C(N=6)$ ], and 7 patients had alcoholic cirrhosis. The main morphological diagnoses as well as pertinent clinical and biochemical parameters of the patients are summarized in Table 1. During the same period, 14 normal spleen specimens were taken from patients who had suffered traumatic splenic rupture without any signs of liver disease or any other diseases. All samples used in this study were obtained with the approval of the Ethics Committee of Research in the Second Affiliated Hospital, Fourth Military Medical University, and all patients gave written informed consent to participate.

\section{Histological and immunohistochemical analyses}

All specimens were taken from the tissues near the hilum of the spleen, which were those most directly influenced by the high portal hypertension. After $10 \%$ formalin fixation, the tissues were embedded in paraffin, cut into 5- $\mu \mathrm{m}$ sections and routinely stained with Masson trichrome and neighboring sections were used for immunolocalization. Endogenous peroxidase activity was blocked with $0.3 \%$ hydrogen peroxide for $20 \mathrm{~min}$. For antigen retrieval, slides were heated in a microwave oven for $10 \mathrm{~min}$ in $10 \mathrm{mM}$ citrate buffer, $\mathrm{pH}$ 6.0. Nonspecific binding was inhibited by incubation with blocking buffer at room temperature for 30 $\min$. The sections were then incubated at $4^{\circ} \mathrm{C}$ overnight with primary antibodies against YKL-40 (1:150 dilution, rabbit polyclonal IgG; Quidel, USA) or against MMP-9 (1:200 dilution, rabbit monoclonal IgG; Clone ID: EP1254, Epitomics, USA). After a brief wash with phosphate-buffered saline (PBS), the sections were incubated for $30 \mathrm{~min}$ with a peroxidase-labeled polymer conjugated to antirabbit immunoglobulins (DAKO EnVision System/HRP K4010; Dako Cytomation, Denmark). The final detection was performed using 3,3'-diaminobenzidine (DAB) as the chromogen and $3 \%$ hematoxylin as the counterstain. Breast cancer tissue was used as positive control (immunoreactivity was noted in the tumor cells). A negative control without a primary antibody was used.

For YKL-40 and MMP-9, mainly expressed in macrophages but not in lymphocytes, expression of $\mathrm{YKL}-40$ / MMP-9 was tested according to the percentage of positivestained cells. A positive result was defined when positivestained cells were more than $10 \%$ of the total cells in one visual field at 400X magnification. The degree of fibrosis was evaluated based on the percentage of blue-stained fiber area. All images were analyzed using the Image pro plus 6.0 software (Media Cybernetics, USA).

\section{Statistical analysis}

Statistical analysis was performed with the SPSS software (SPSS Standard version 17.0; SPSS Inc., USA). The Student $t$-test and the $X^{2}$ test were used to evaluate the statistical significance using YKL-40 as a clinicopathologic 
parameter for the patients. The Spearman $\rho$ test was performed to evaluate correlation between YKL-40, MMP-9, free portal pressure (FPP), and degree of spleen fibrosis. $P$ values of less than 0.05 were considered to indicate statistical significance.

\section{Results}

\section{Evaluation of YKL-40 expression in enlarged spleen}

The expression of YKL-40 in 48 splenomegaly specimens and 14 normal spleen tissues was investigated by immunohistochemistry. YKL-40 was successfully detected in $33(68.8 \%)$ of 48 splenomegaly specimens and in 3 (21.4\%) of 14 normal spleen tissues. Positive expression of YKL-40 occurred in the cytoplasm. The tissues stained by YKL-40 antigen were in areas such as the splenic marginal zone and red pulp, but seldom was detected in splenic corpuscles. According to cell morphology, karyoplasmic ratio and the location of positive-expressed cells, the positive-stained cells were macrophages. Positive-stained cells were also detected in some vascular smooth muscle cells (Figure 1).

\section{The relationship between overexpression of YKL-40 and the clinical features of portal hypertension}

The association of YKL-40 overexpression with the clinical characteristics of the patient cohort was further evaluated and is summarized in Tables 1 and 2 . The immunohistochemical expression of YKL-40 was significantly higher in the spleen of portal hypertension patients than in normal spleen. Among portal hypertension patients, there was no significant difference in red blood cells, white blood cells, platelets, serum albumin, or serum glutamic pyruvic transaminase between the YKL-40 positive-stained group and the $\mathrm{YKL}-40$ negative-stained group. But serum total bilirubin (TBIL) [39.60 (21.40-74.50) vs 33.08 (15.20-51.20)],
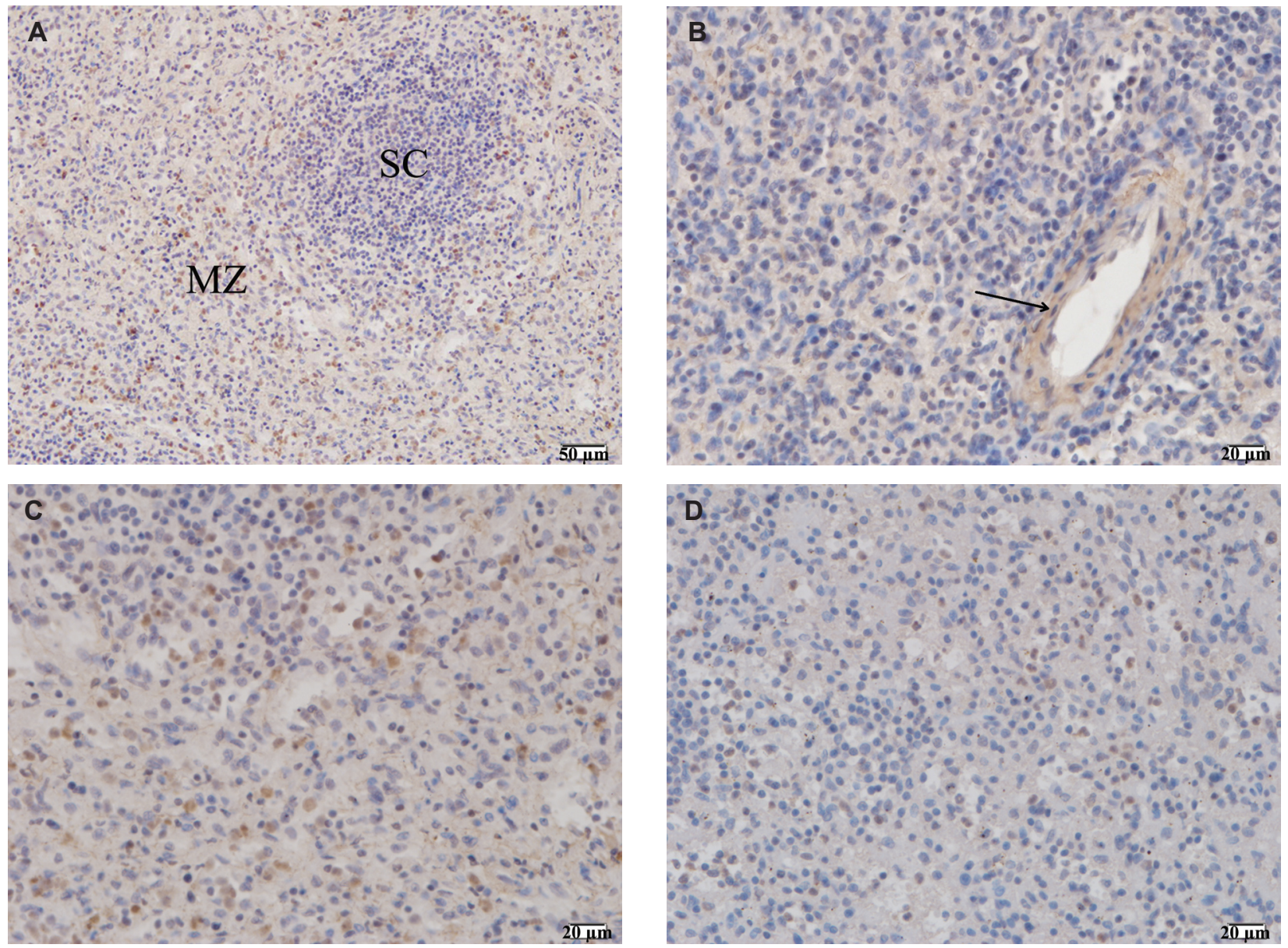

Figure 1. Detection of the expression of YKL-40 by immunohistochemical staining. Positive expression (brown) of $Y K L-40$ occurred in the cytoplasm. A, Expression of YKL-40 in the marginal zone (MZ) of the spleen of a patient with portal hypertension; lack of YKL-40 expression in splenic corpuscle (SC). B, Expression of YKL-40 in vascular smooth muscle cells (arrow). C, Expression of YKL-40 in spleen tissue from a patient with portal hypertension. $D$, Expression of YKL-40 in normal spleen. 
serum glutamic oxalacetic transaminase (GOT) [40 (17110) vs 30 (17-74)] were significantly higher in the YKL-40 positive-stained group than in the YKL-40 negative-stained group (Table 1). The overexpression of YKL-40 did not correlate with patient age ( $\leq 44$ years old $v s>44$ years old), gender, causes of cirrhosis (hepatitis $B$, hepatitis $C$, and alcoholic cirrhosis) and the severity of esophageal varices (none, slight, moderate to severe; Table 2). However, overexpression of YKL-40 was significantly related to Child-Pugh classification $(P=0.000)$. When the expression of $Y K L-40$ in different Child-Pugh classifications was compared by the chi-square method, it was found that overexpression of YKL-40 in Child $B$ and Child $C$ patients was higher $(P=0.000$, $\mathrm{P}=0.003$, respectively) than that in Child $A$ patients. No difference in expression was found between Child $B$ and in Child $C$ patients $(P=$ 0.789; data not shown in Table 2). A significant correlation between expression of YKL-40 and FPP was also obtained by the Spearman $\rho$ test (correlation coefficient $=0.499, \mathrm{P}<0.01$; Figure 2).

\section{Correlation of the overexpression of YKL-40 and MMP-9 in fibrosis}

It has been reported that YKL-40 is able to activate the release of MMP-9 in alveolar macrophages from patients with chronic obstructive pulmonary disease (17) and from the human monocytic cell line THP-1 (18) when these cells were exposed to YKL-40. But a recent study (19) showed that YKL-40 in infiltrating macrophages inhibits MMP-1 activity and accelerates fibril formation in the vicinity of macrophages to trap macrophages in adipose tissue. To determine whether YKL40 is able to mediate the activation of MMP-9 in spleen of patients with portal hypertension, expression of MMP-9 and its relationship with YKL-40 were investigated in spleen tissue with portal hypertension by immunohistochemistry. Positive-stained cells were also located mainly in the red pulp and marginal zone but scarcely in the splenic corpuscle. Interestingly, expression of MMP-9 in normal spleen was indeed higher than in enlarged spleen (37.39 \pm 0.75 vs $25.11 \pm 0.83 \% ; P<0.01)$, and a significant correlation was found between $\mathrm{YKL}-40$ and MMP-9 (correlation coefficient $=-0.839, \mathrm{P}<$ 0.01; Figure 3).

Histomorphological analysis was carried out to detect the presence of fibrosis in the spleen by Masson trichrome staining, and a considerable amount of fibrosis extending to the entire splenic parenchyma was found in portal hypertension patients compared to normal persons (17.07 $\pm 5.03 \mathrm{vs}$ $5.11 \pm 0.73 \%, P<0.01)$. Additionally, the Spearman $\rho$ test showed that expression of YKL-40 was correlated with the fibrosis area of the spleen (correlation coefficient $=0.857$, $P<0.01$; Figure 4).
Table 1. Clinical and biochemical characteristics of the patients with portal hypertension.

\begin{tabular}{lcc}
\hline & $\begin{array}{c}\text { YKL-40 positive-stained } \\
(\mathrm{N}=33)\end{array}$ & $\begin{array}{c}\text { YKL-40 negative-stained } \\
(\mathrm{N}=15)\end{array}$ \\
\hline Age (years) & $45(22-69)$ & $40(19-58)$ \\
Red blood cells $\left(10^{12} / \mathrm{L}\right)$ & $3.59(2.64-5.02)$ & $3.41(2.57-3.90)$ \\
White blood cells $\left(10^{9} / \mathrm{L}\right)$ & $1.68(0.10-7.04)$ & $2.02(0.77-3.11)$ \\
Platelets $\left(10^{9} / \mathrm{L}\right)$ & $43(20-119)$ & $50(11-94)$ \\
Serum albumin $(\mathrm{g} / \mathrm{L})$ & $31.7(25.8-41.8)$ & $33.6(27-38.7)$ \\
Serum TBIL $(\mu \mathrm{M})$ & $39.6(21.4-74.5)$ & $33.1(15.2-51.2)^{*}$ \\
Serum GPT $(\mathrm{U} / \mathrm{L})$ & $27(9-75)$ & $21(11-61)$ \\
Serum GOT $(\mathrm{U} / \mathrm{L})$ & $40(17-110)$ & $30(17-74)^{*}$ \\
\hline
\end{tabular}

Data are reported as median (range). TBIL = total bilirubin; GPT = glutamicpyruvic transaminase; GOT = glutamic-oxalacetic transaminase. ${ }^{*} \mathrm{P}<0.05$ compared to $\mathrm{YKL}-40$ positive-stained group (Student $t$-test).

Table 2. Clinical significance of YKL-40 overexpression in portal hypertension.

\begin{tabular}{lcc}
\hline Clinicopathologic features & Total cases & Overexpression of YKL-40 \\
\hline Normal spleen & 14 & $3 / 14(21.4 \%)^{*}$ \\
No. of patients & 48 & $33 / 48(68.8 \%)$ \\
Age (years) & & \\
$\quad \leq 44$ & 27 & $16 / 27(59.3 \%)$ \\
$>44$ & 21 & $17 / 21(81.0 \%)$ \\
Gender & & \\
$\quad$ Male & 33 & $24 / 33(72.7 \%)$ \\
Female & 15 & $9 / 15(60.0 \%)$ \\
Cause of cirrhosis & & \\
$\quad$ Hepatitis B & 35 & $24 / 35(68.6 \%)$ \\
$\quad$ Hepatitis C & 6 & $4 / 6(66.7 \%)$ \\
$\quad$ Alcoholic cirrhosis & 7 & $5 / 7(71.4 \%)$ \\
Severity of esophageal varices & & $1 / 3(33.3 \%)$ \\
$\quad$ None & 3 & $6 / 9(66.7 \%)$ \\
Slight & 9 & $26 / 36(72.2 \%)$ \\
$\quad$ Moderate/Severe & 36 & $3 / 14(21.4 \%)^{*}$ \\
Child-Pugh classification & & $22 / 26(84.6 \%)^{*}$ \\
$\quad$ Child A & 14 & $8 / 8(100 \%)^{*}$ \\
Child B & 26 & \\
Child C & 8 & \\
\hline
\end{tabular}

${ }^{*} \mathrm{P}<0.05$ compared to patients with portal hypertension or degrees of ChildPugh classification ( $\mathrm{X}^{2}$ test). 


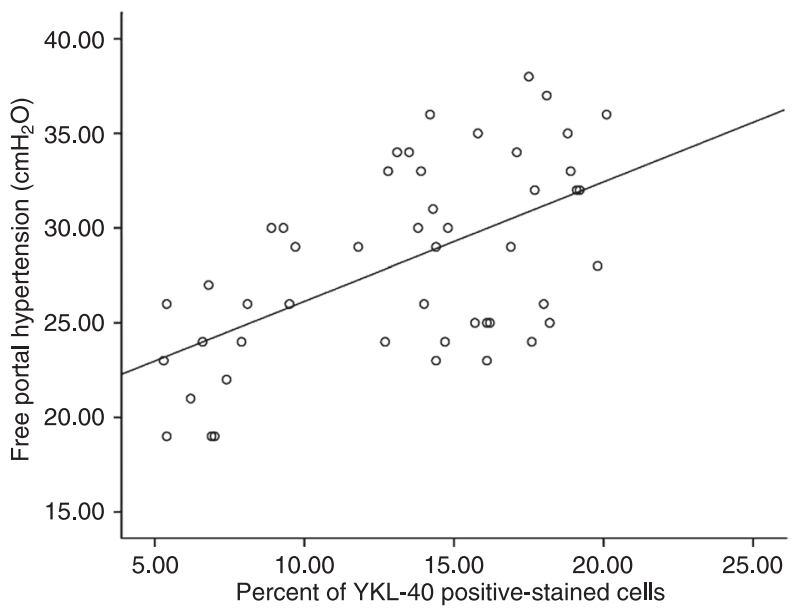

Figure 2. Correlation between the expression of $\mathrm{YKL}-40$ and free portal pressure. $R=0.499 ; P<0.01$ were obtained with the Spearman $\rho$ test.
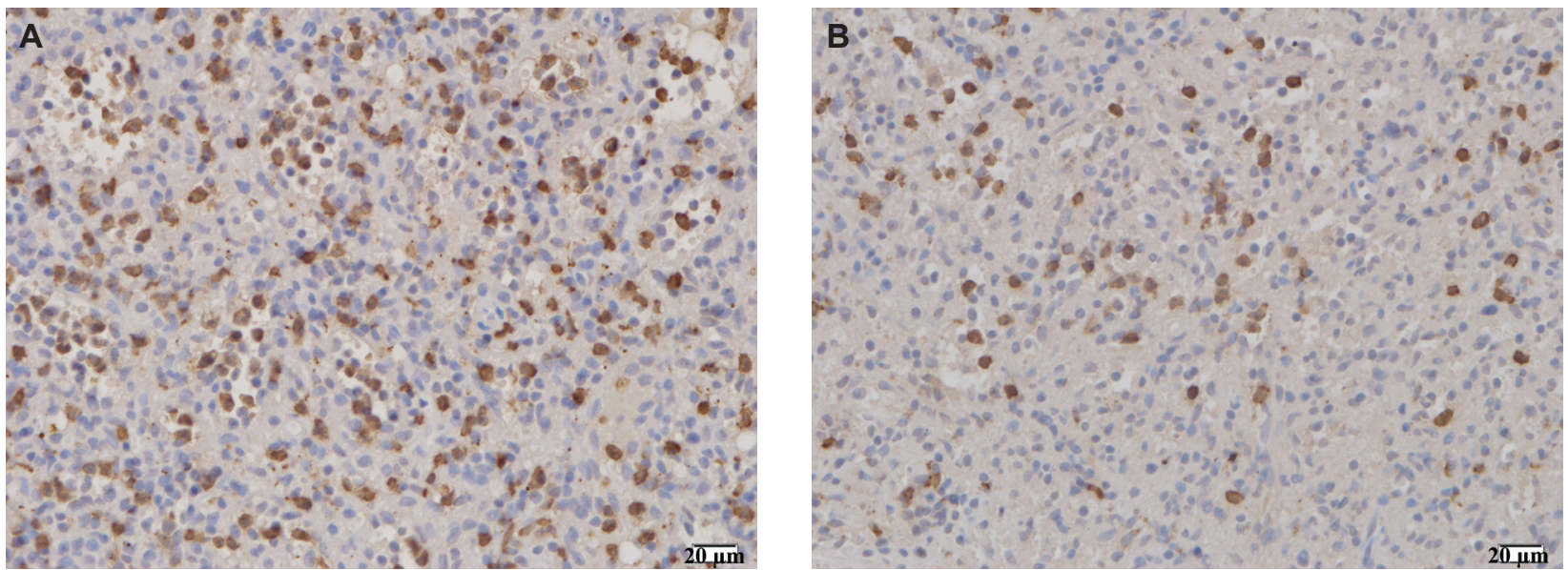

\section{C}

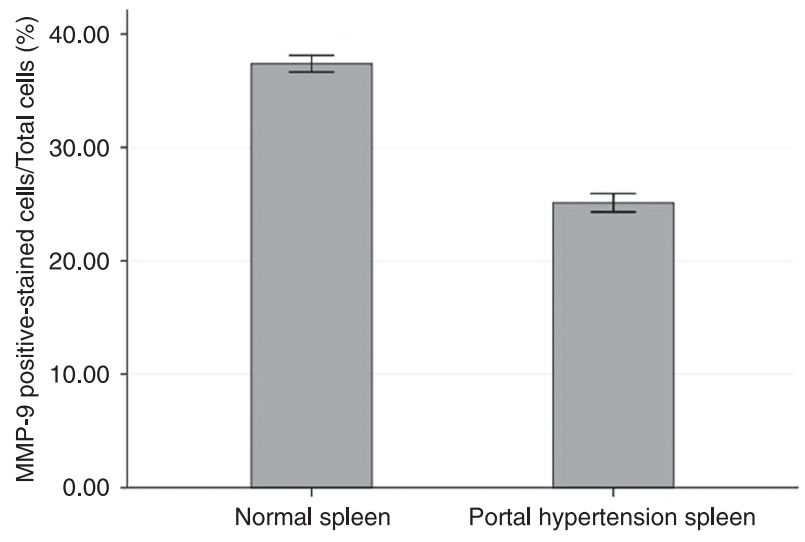

D

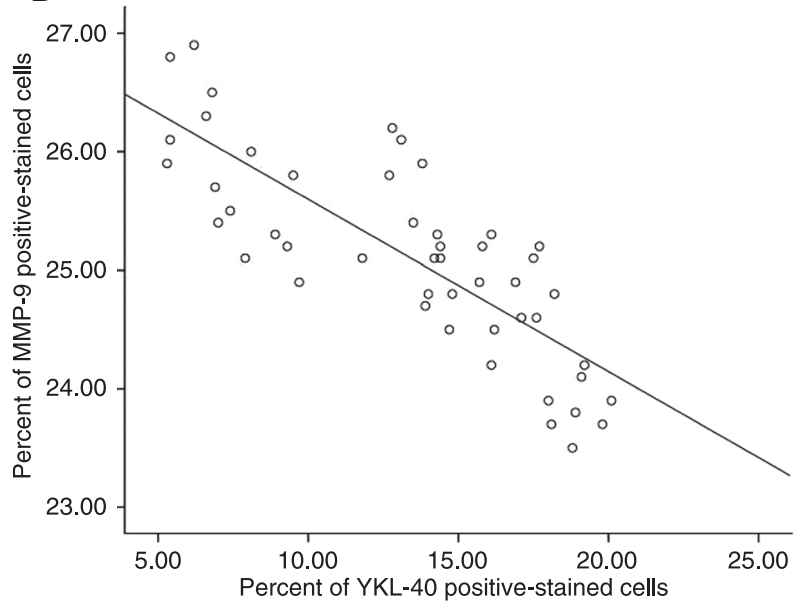

Figure 3. Expression of metalloproteinase-9 (MMP-9) in the spleen. Positive expression (brown) of MMP-9 occurred in the cytoplasm. $A$, Normal spleen; $B$, spleen from a patient with portal hypertension; $C$, comparison of MMP-9 between a normal spleen and spleen tissue from a patient with portal hypertension. Data are reported as means $\pm \mathrm{SD}$. $D$, Correlation between YKL-40 and MMP-9 expressed in spleen tissue from a patient with portal hypertension $(R=-0.839, P<0.01$; Spearman $\rho$ test $)$. 

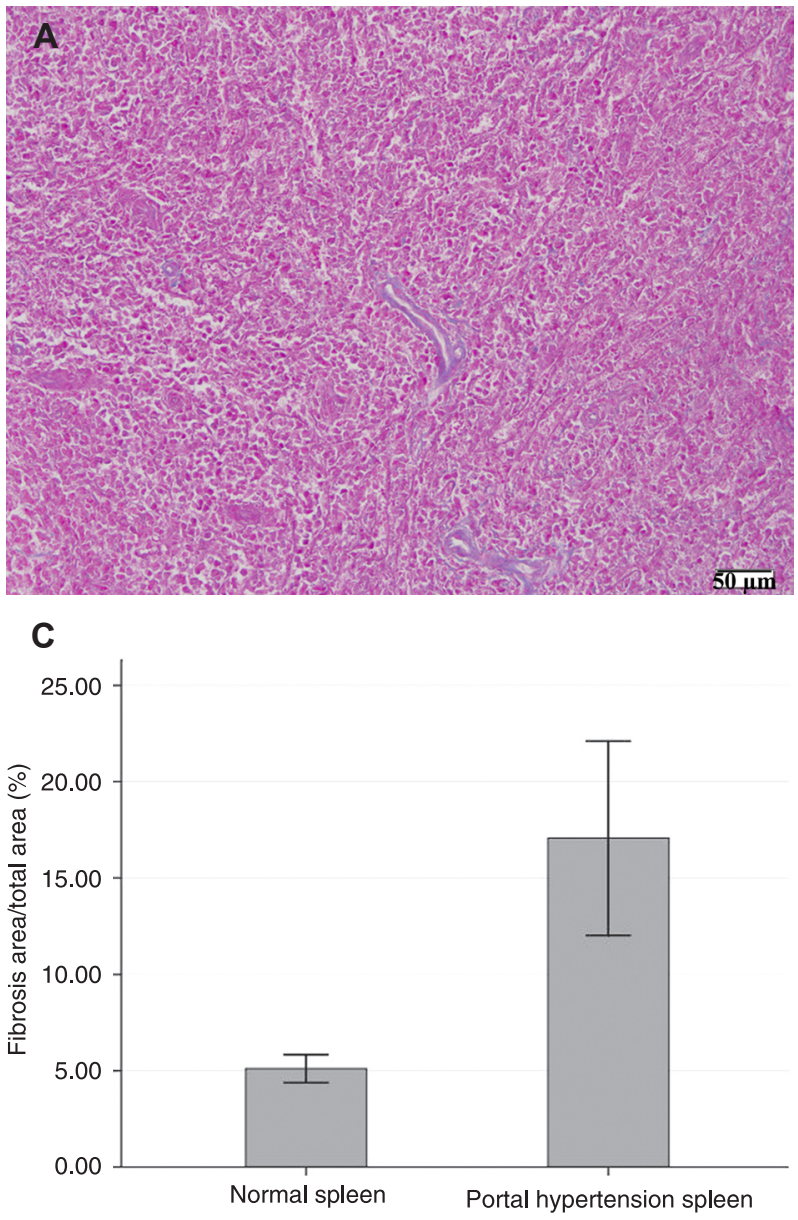
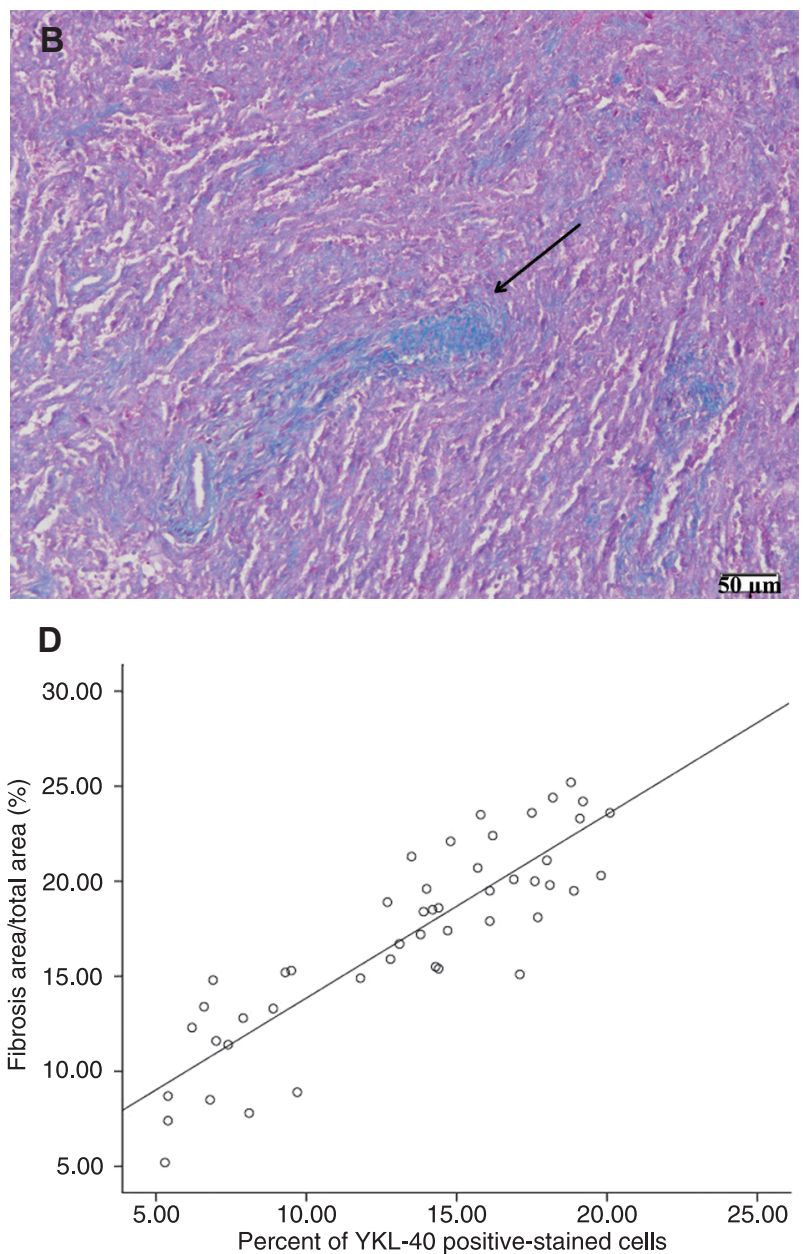

Figure 4. Detection of fiber in the spleen by Masson trichrome staining. $A$, Normal spleen. $B$, Spleen from a patient with portal hypertension. The arrow indicates blue staining of the fiber. $C$, Comparison of the amount of fiber between a normal spleen and spleen tissue from a patient with portal hypertension. $D$, Correlation between expression of YKL-40 and fiber in spleen tissue from a patient with portal hypertension $(R=0.857, P<0.01$; Spearman $\rho$ test $)$.

\section{Discussion}

YKL-40 was first detected by Johansen et al. (3) as an ECM glycoprotein in a human osteosarcoma MG63 cell line. So far, expression of YKL-40 has been detected in some kinds of cancer cells $(20,21)$, macrophages $(22,23)$, fetal cells in the human embryo (24), tumor-associated macrophages (25), in the late differentiation of neutrophil activation (26), in cartilage cells $(4,27)$, in the differentiation of vascular smooth muscle cells $(28,29)$, and fibroblast-like chondrocytes $(26,30)$ but not in lymphocytes. As to tissue remodeling, YKL-40 has been shown to be expressed by a variety of cells during chronic inflammatory conditions (31) and its serum concentration is associated with the risk and severity of asthma $(10,32)$, acute myocardial infarction (33), rheumatoid arthritis (34), and atherosclerosis (35). Functionally, YKL-40 is secreted by activated macrophages during early and late stages of differentiation in vitro $(6,22)$. In vivo, YKL-40 mRNA is found in a subpopulation of macrophages in tissues with inflammation and matrix remodeling (36). Johansen et al. (9) and Berres et al. (37) have reported that serum YKL-40 is associated with severity of liver fibrosis and can be considered to be a noninvasive fibrosis marker. Our study initially showed that the expression of YKL-40 was significantly higher in the spleen of patients with portal hypertension than that in the spleen of normal people. In the spleen, YKL-40 positive-stained cells were detected mainly in the marginal zone and red pulp in which large macrophages were located, and scarcely found in the splenic corpuscle where most lymphocytes were located. Based on cell morphology, karyoplasmic ratio and the location of the positive-expressed cells, they were identified as macrophages. This result is consistent with previous studies. Nishikawa and Millis (29) have reported that YKL-40 is a 
novel adhesion and migration factor for vascular cells. In our study, positive-stained vascular muscle cells were also detected in some individually proliferating vessels. However, positive-stained cells were not found in most proliferating vessels, although smooth muscle proliferation was their common feature. This demonstrated that YKL-40 may be engaged in vascular remodeling when there is a direct irritation of the hyperdynamic circulation or fibrosis-promoting factors in the blood circulation, but YKL-40 may not be the main factor stimulating smooth muscle proliferation in the splenomegaly of portal hypertension. Because the spleen specimens were taken from patients suffering from cirrhosis of different origins, the causes of cirrhosis were also evaluated. However, no difference was found $(P=0.982)$ demonstrating that there was no relationship between overexpression of YKL-40 and causes of cirrhosis.

Normally, fibers support the structure of the spleen and represent the blood spleen barrier. However, fiber proliferates largely in splenomegaly of portal hypertension. Thus, it will break the normal structure of the spleen and block blood flow into the spleen. In addition, fiber proliferation limits further expansion of the sinusoids to accept more blood and stimulates compensatory angiogenesis. More importantly, fiber proliferation increases the mechanical damage to blood cells and clearance of blood cells by macrophage, which will lead to hypersplenism. Thus, we explored whether splenomegaly associated with portal hypertension was driven by fibrogenesis. Our results suggested that this could be the case and statistical analysis also indicated that overexpression of YKL-40 was significantly associated with the degree of fibrosis in the spleen associated with portal hypertension. This may well demonstrate that YKL-40 is an important factor contributing to the process of spleen fibrosis. The Spearman $\rho$ test also showed that overexpression of YKL-40 was correlated with FPP and Child-Pugh classification. It has been reported (38) that if the spleen remained in the artificial system of portal hypertension, fibrosis of the spleen would be increased and its function would disappear gradually, but if it migrated to the iliac vessels with normal blood pressure, the fibrosis could be gradually reduced. This indicates that portal hypertension might indirectly be the immediate cause of spleen fibrosis. The correlation between YKL-40 and FPP showed that the direct stimulation of portal pressure may be one of the factors involved in the overexpression of YKL-40. As to the correlation with Child-Pugh classification, the more seriously liver function was impaired, the more $\mathrm{YKL}-40$ was expressed. Serum TBIL and GOT could reflect liver func-

\section{References}

1. McCormick PA, Murphy KM. Splenomegaly, hypersplenism and coagulation abnormalities in liver disease. Baillieres Best Pract Res Clin Gastroenterol 2000; 14: 1009-1031. tion and injury to the hepatocytes. The difference in serum GOT/serum TBIL between the YKL-40 positive-expressed group and $\mathrm{YKL}-40$ negative-expressed group may also indirectly demonstrate the influence of liver function on the overexpression of YLK-40 in splenomegaly. Although this may not be the full reason for the result of our study, it can be hypothesized that with the deterioration of liver function, some factors causing liver fibrosis may flow into the spleen with the blood circulation and stimulate the expression of YKL-40.

MMPs are important factors in the ECM. Under normal physiological conditions, they are thought to be of great importance in the maintenance of connective tissue integrity. MMP-9, a member of the MMP family, was reported to have proteolytic activity against connective tissue proteins, and has been suggested to be important in the connective tissue remodeling processes associated with atherogenesis and plaque rupture (39). Theoretically, we hypothesized that $\mathrm{YKL}-40$ promoted fibrosis in the spleen by inhibiting expression of MMP-9 in the process of portal hypertension. Interestingly, the results agreed with this hypothesis and led us to believe that inhibition of MMP- 9 by YKL-40 may be the key molecular mechanism involved in the development of fibrosis in splenomegaly derived from portal hypertension. However, further studies are needed.

In our study, we only investigated the function of YKL40 in fibrogenesis, one aspect of splenomegaly caused by portal hypertension. Although we detected overexpression of YKL-40 in some individual vascular smooth muscle cells, the effects of YKL-40 on angiogenesis are not yet fully known. As to hypersplenism, the lack of differences in red blood cells, white blood cells and platelets between the YKL-40 positive-stained group and the YKL-40 negativestained group may indicate that YKL-40 has no impact on this condition, but more studies are needed.

In conclusion, YKL-40 is an important factor in the spleen fibrogenesis occurring in portal hypertension. Moreover, combined with the routine treatment of portal hypertension (modifying liver function, lowering free portal hypertension, etc.), development and application of YKL-40 inhibitors or YKL-40 antibody may be an effective target of therapy for splenomegaly. Further investigations are in progress.

\section{Acknowledgments}

Research supported by the National Natural Science Foundation of China (\#81172287).

2. Mutchnick MG, Lerner E, Conn HO. Effect of portacaval anastomosis on hypersplenism. Dig Dis Sci 1980; 25: 929938. 
3. Johansen JS, Williamson MK, Rice JS, Price PA. Identification of proteins secreted by human osteoblastic cells in culture. J Bone Miner Res 1992; 7: 501-512.

4. Hakala BE, White C, Recklies AD. Human cartilage gp-39, a major secretory product of articular chondrocytes and synovial cells, is a mammalian member of a chitinase protein family. J Biol Chem 1993; 268: 25803-25810.

5. Shackelton LM, Mann DM, Millis AJ. Identification of a 38$\mathrm{kDa}$ heparin-binding glycoprotein (gp38k) in differentiating vascular smooth muscle cells as a member of a group of proteins associated with tissue remodeling. $\mathrm{J}$ Biol Chem 1995; 270: 13076-13083.

6. Renkema GH, Boot RG, Au FL, Donker-Koopman WE, Strijland A, Muijsers AO, et al. Chitotriosidase, a chitinase, and the 39-kDa human cartilage glycoprotein, a chitin-binding lectin, are homologues of family 18 glycosyl hydrolases secreted by human macrophages. Eur J Biochem 1998; 251: 504-509.

7. Bigg HF, Wait R, Rowan AD, Cawston TE. The mammalian chitinase-like lectin, YKL-40, binds specifically to type I collagen and modulates the rate of type I collagen fibril formation. J Biol Chem 2006; 281: 21082-21095.

8. Funkhouser JD, Aronson NN Jr. Chitinase family GH18: evolutionary insights from the genomic history of a diverse protein family. BMC Evol Biol 2007; 7: 96.

9. Johansen JS, Christoffersen P, Moller S, Price PA, Henriksen $\mathrm{JH}$, Garbarsch C, et al. Serum YKL-40 is increased in patients with hepatic fibrosis. J Hepatol 2000; 32: 911-920.

10. Chupp GL, Lee CG, Jarjour N, Shim YM, Holm CT, He S, et al. A chitinase-like protein in the lung and circulation of patients with severe asthma. N Engl J Med 2007; 357: 20162027.

11. Furuhashi K, Suda T, Nakamura $Y$, Inui N, Hashimoto D, Miwa S, et al. Increased expression of YKL-40, a chitinaselike protein, in serum and lung of patients with idiopathic pulmonary fibrosis. Respir Med 2010; 104: 1204-1210.

12. De Ceuninck F, Gaufillier S, Bonnaud A, Sabatini M, Lesur C, Pastoureau P. YKL-40 (cartilage gp-39) induces proliferative events in cultured chondrocytes and synoviocytes and increases glycosaminoglycan synthesis in chondrocytes. Biochem Biophys Res Commun 2001; 285: 926-931.

13. Shao R, Hamel K, Petersen L, Cao QJ, Arenas RB, Bigelow C, et al. YKL-40, a secreted glycoprotein, promotes tumor angiogenesis. Oncogene 2009; 28: 4456-4468.

14. Moschowitz $\mathrm{E}$. The pathogenesis of splenomegaly in hypertension of the portal circulation; congestive splenomegaly. Medicine 1948; 27: 187-221.

15. Bolognesi M, Merkel C, Sacerdoti D, Nava V, Gatta A. Role of spleen enlargement in cirrhosis with portal hypertension. Dig Liver Dis 2002; 34: 144-150.

16. Bayraktar Y, Balkanci F, Uzunalimoglu B, Gokoz A, Koseoglu $\mathrm{T}$, Batman $\mathrm{F}$, et al. Is portal hypertension due to liver cirrhosis a major factor in the development of portal hypertensive gastropathy? Am J Gastroenterol 1996; 91: 554-558.

17. Letuve S, Kozhich A, Arouche N, Grandsaigne M, Reed $\mathrm{J}$, Dombret MC, et al. YKL-40 is elevated in patients with chronic obstructive pulmonary disease and activates alveolar macrophages. J Immunol 2008; 181: 5167-5173.

18. Michelsen AE, Rathcke CN, Skjelland M, Holm S, Ranheim T, Krohg-Sorensen K, et al. Increased YKL-40 expression in patients with carotid atherosclerosis. Atherosclerosis 2010; 211: 589-595.
19. Iwata $T$, Kuwajima $M$, Sukeno A, Ishimaru $N$, Hayashi $Y$, Wabitsch $M$, et al. YKL-40 secreted from adipose tissue inhibits degradation of type I collagen. Biochem Biophys Res Commun 2009; 388: 511-516.

20. Bi J, Lau SH, Lv ZL, Xie D, Li W, Lai YR, et al. Overexpression of YKL-40 is an independent prognostic marker in gastric cancer. Hum Pathol 2009; 40: 1790-1797.

21. Yamac D, Ozturk B, Coskun U, Tekin E, Sancak B, Yildiz R, et al. Serum YKL-40 levels as a prognostic factor in patients with locally advanced breast cancer. Adv Ther 2008; 25: 801-809.

22. Rehli M, Niller HH, Ammon C, Langmann S, Schwarzfischer $\mathrm{L}$, Andreesen R, et al. Transcriptional regulation of $\mathrm{CHI} 3 \mathrm{~L} 1$, a marker gene for late stages of macrophage differentiation. J Biol Chem 2003; 278: 44058-44067.

23. Rehli M, Krause SW, Andreesen R. Molecular characterization of the gene for human cartilage gp-39 (CHI3L1), a member of the chitinase protein family and marker for late stages of macrophage differentiation. Genomics 1997; 43: 221-225.

24. Johansen JS, Hoyer PE, Larsen LA, Price PA, Mollgard K. YKL-40 protein expression in the early developing human musculoskeletal system. J Histochem Cytochem 2007; 55: 1213-1228.

25. Junker N, Johansen JS, Andersen CB, Kristjansen PE. Expression of YKL-40 by peritumoral macrophages in human small cell lung cancer. Lung Cancer 2005; 48: 223-231.

26. Volck B, Price PA, Johansen JS, Sorensen O, Benfield TL, Nielsen $\mathrm{HJ}$, et al. YKL-40, a mammalian member of the chitinase family, is a matrix protein of specific granules in human neutrophils. Proc Assoc Am Physicians 1998; 110: 351-360.

27. Volck B, Johansen JS, Stoltenberg M, Garbarsch C, Price $\mathrm{PA}$, Ostergaard M, et al. Studies on YKL-40 in knee joints of patients with rheumatoid arthritis and osteoarthritis. Involvement of YKL-40 in the joint pathology. Osteoarthritis Cartilage 2001; 9: 203-214.

28. Malinda KM, Ponce L, Kleinman HK, Shackelton LM, Millis AJ. Gp38k, a protein synthesized by vascular smooth muscle cells, stimulates directional migration of human umbilical vein endothelial cells. Exp Cell Res 1999; 250: 168-173.

29. Nishikawa KC, Millis AJ. gp38k (CHI3L1) is a novel adhesion and migration factor for vascular cells. Exp Cell Res 2003; 287: 79-87.

30. Dasuri K, Antonovici M, Chen K, Wong K, Standing K, Ens $\mathrm{W}$, et al. The synovial proteome: analysis of fibroblast-like synoviocytes. Arthritis Res Ther 2004; 6: R161-R168.

31. Ringsholt M, Hogdall EV, Johansen JS, Price PA, Christensen LH. YKL-40 protein expression in normal adult human tissues - an immunohistochemical study. J Mol Histol 2007; 38: 33-43.

32. Ober C, Tan Z, Sun Y, Possick JD, Pan L, Nicolae R, et al. Effect of variation in CHI3L1 on serum YKL-40 level, risk of asthma, and lung function. N Engl J Med 2008; 358: 16821691.

33. Nojgaard C, Host NB, Christensen IJ, Poulsen SH, Egstrup $\mathrm{K}$, Price PA, et al. Serum levels of YKL-40 increases in patients with acute myocardial infarction. Coron Artery Dis 2008; 19: 257-263.

34. Knudsen LS, Klarlund M, Skjodt $H$, Jensen T, Ostergaard $M$, Jensen KE, et al. Biomarkers of inflammation in patients with unclassified polyarthritis and early rheumatoid arthritis. 
Relationship to disease activity and radiographic outcome. J Rheumatol 2008; 35: 1277-1287.

35. Kucur M, Isman FK, Karadag B, Vural VA, Tavsanoglu S. Serum YKL-40 levels in patients with coronary artery disease. Coron Artery Dis 2007; 18: 391-396.

36. Baeten D, Boots AM, Steenbakkers PG, Elewaut D, Bos E, Verheijden GF, et al. Human cartilage gp-39+,CD16+ monocytes in peripheral blood and synovium: correlation with joint destruction in rheumatoid arthritis. Arthritis Rheum 2000; 43: 1233-1243.

37. Berres ML, Papen S, Pauels K, Schmitz P, Zaldivar MM, Hellerbrand $\mathrm{C}$, et al. A functional variation in $\mathrm{CHI} 3 \mathrm{~L} 1$ is as- sociated with severity of liver fibrosis and YKL-40 serum levels in chronic hepatitis C infection. J Hepatol 2009; 50: 370-376.

38. Wang Q, Cheng QJ, Guo QP. Comparison of partial splenomegaly preservation in situ with heterotopic transplantation in histology and function for portal hypertension. Beng $\mathrm{Bu} Y i$ Xue Yuan Xue Bao 1991; 16: 55-56 (in Chinese).

39. Zhang B, Ye S, Herrmann SM, Eriksson P, de Maat M, Evans $A$, et al. Functional polymorphism in the regulatory region of gelatinase $B$ gene in relation to severity of coronary atherosclerosis. Circulation 1999; 99: 1788-1794. 